\title{
MODIFIED SELVESTER QRS SCORE REDUCTION FOR PREDICTION OF MYOCARDIAL SALVAGE FOLLOWING SUCCESSFUL REPERFUSION OF ACUTE ST ELEVATION MYOCARDIAL INFARCTION
}

\author{
Ahmed Shafie Ammar MD ${ }^{(1)}$, Islam Abd El-Moneem El-Sherbiny MD ${ }^{(1)}$, Islam ElSayed Shehata \\ $M D^{(1)}$, Cheng-I-Cheng MD ${ }^{(2)}$, Islam Ghanem Ahmed Ghanem MSc ${ }^{(1)}$ \\ (1) Department of Cardiology, Faculty of medicine, Zagazig University, Egypt. \\ (2) Chang Gung Memorial Hospital, Kaohsiung, Taiwan.
}

\begin{abstract}
Background: Achieving optimal angiographic coronary flow after acute ST elevation myocardial infarction (STEMI) isn't the best parameter of success. Perfusion of the microvasculature is more important. QRS score plays an important role for early risk stratification for STEMI. It is a simple electrocardiographic (ECG) parameter for assuring the presence or absence of microvascular obstruction.
\end{abstract}

Aim of the work: The aim of this clinical study is to validate the 90 minutes modified Selvester QRS score reduction as a reliable predictor of myocardial salvage, represented by 3 months global longitudinal strain (GLS) value, following successful reperfusion of acute STEMI.

Material/Methods: The study population included 400 patients presented with first acute STEMI with successful reperfusion by thrombolysis (Group I- 200 patients: mean age $=57.1 \pm 11.6$ years) or primary percutaneous intervention (PPCI) (Group II- 200 patients: mean age $=58.2 \pm 9.8$ years). Basal and 90 minutes after reperfusion electrocardiography was done with assessment of ST resolution and modified Selvester QRS score. Basal and 3 months follow up echocardiography was performed with assessment of ejection fraction (EF) and GLS as an indicator for myocardial salvage with its impact on long-term clinical outcome.

Results: 90 minutes ST resolution and QRS score reduction were significantly higher in PPCI group (P.: 0.04*, $0.03 *$ ). Patients in group I had non-significant improvement of EF (P.: 0.22) during follow-up, but highly significant improvement of GLS $\left(\mathrm{P} .:<0.001^{* *}\right)$ compared to the basal echocardiographic study. Patients in group II had significant improvement of EF (P.: 0.01*) during follow-up, and highly significant improvement of GLS (P.: $\left.<0.001^{* *}\right)$ compared to the basal echocardiographic study. As regarding correlation with 3 months GLS value, there was highly significant negative correlation between 3months GLS and (ST resolution and QRS score reduction) (P.: $<0.001^{* *}$ ). Receiver operating characteristics $(\mathrm{ROC})$ curve analysis shows that 90 minutes QRS score reduction has the best cut off value of $70 \%$ to predict 3months GLS improvement with $80 \%$ sensitivity and $79 \%$ specificity.

Conclusions: Modified Selvester QRS score reduction 90 minutes after reperfusion is a cheap bedside ECG parameter added to ST resolution, can be considered as a reliable predictor of future myocardial salvage with its impact on long-term clinical outcome and modifying management strategies.

Keywords: Modified Selvester QRS score • Myocardial infarction• Myocardial salvage

Corresponding author: Islam Ghanem Ahmed Ghanem, 01100224180, 01001270412. dr.islam_2010@yahoo.com

\section{INTRODUCTION}

A chieving optimal angiographic coronary flow after acute ST elevation myocardial infarction (STEMI) isn't the best parameter of success. Perfusion of the microvasculature is more important. Poor tissue perfusion has poor prognostic impact ${ }^{(1)}$. QRS score appears to be important in the early risk stratification for STEMI ${ }^{(2)}$. QRS score derived from simple and widely available electrocardiogram (ECG) may be a useful parameter for assuring the presence of microvascular obstruction ${ }^{(3)}$. The modified Selvester QRS score (Table 1) based on ECG criteria capable of generating a total of 29 points with each point in the score corresponding to $3 \%$ of the left ventricular (LV) $\operatorname{mass}^{(4)}$.

Global longitudinal strain (GLS) is considered an effective tool to assess LV systolic function better than LV ejection fraction (EF) assessed by two-dimensional (2D) echocardiography ${ }^{(5)}$, even in diastolic heart failure after acute MI ${ }^{(6)}$. Vartdal et al. (2007) (7) showed that global strain is correlated with final infarction size. 
Global longitudinal strain (GLS) is calculated as the range of the values of different LV segments from the three apical views ${ }^{(8)}$. GLS measures less than $(-20 \%)$ is considered abnormal ${ }^{(9)}$.

The aim of this clinical study is to validate the 90 minutes modified Selvester QRS score reduction as a reliable predictor of myocardial salvage, represented by 3 months GLS value, following successful reperfusion of acute STEMI.

\section{SUBJECTS AND METHODS}

- Study design and population:

This clinical study included 400 patients with first time acute STEMI who were admitted to the coronary care unit (CCU) and cathlab. units of cardiology department at Zagazig University, Egypt and Kaohsiung Chang Gung Memorial Hospital, Taiwan during the period from November 2015 to November 2017.

- Inclusion criteria of the study:

We included patients who were admitted with first acute STEMI with successful reperfusion either by PPCI or thrombolytic therapy.

\section{- Exclusion criteria of the study:} (cardiomyopathies).

Failed reperfusion or revascularization.

History of myocardial infarction.

History of previous PCI or coronary artery bypass graft (CABG).

History of heart muscle diseases fibrillation and frequent extra-systoles).

- Previous pacemaker or cardioverterdefibrillator implantation.

Very poor image quality.

- Ethical consideration:

Consent was obtained from every patient after explanation of the procedure.
Medical research and ethics committee approved the study.

\section{- Patient groups:}

We categorized patients into 2 groups:

Group I (200 patients): Patients with first acute STEMI with successful reperfusion by thrombolytic therapy.

Group II (200 patients): Patients with first acute STEMI with successful reperfusion by PPCI.

Successful reperfusion was documented by more than $70 \%$ resolution of ST segment elevation 90 minutes after revascularization ${ }^{(10)}$.

- Data collection:

Data were collected for all patients including:

- Complete history taking: Including name, age, gender, special habits, menstrual state, drug history and previous hospital admission with special consideration to history of risk factors to ischemic heart disease (Hypertension: HTN, diabetes mellitus: DM, smoking, dyslipidemia) and co-morbid conditions.

Thorough clinical examination: All patients were subjected to thorough clinical general and local cardiac examination with special emphasis on hypotension and elevated jugular venous pulse in the presence of clear lung fields.

- Electrocardiography (ECG):

ECG machine (BTL-08 SD1, BTL Industries Inc., USA and MAC 5500 GE Healthcare MUSE v8, USA) was used to record standard 12-lead ECGs. They were recorded at a paper speed of $25 \mathrm{~mm} / \mathrm{second}(\mathrm{s})$ and a gain of $10 \mathrm{~mm} / \mathrm{mv}$.

Twelve-lead ECG was performed directly before and $90 \mathrm{~min}$ after reperfusion. We analyzed the sum of elevations of ST segments in all leads and the modified Selvester QRS score (Table 1) based on ECG criteria capable of generating a total of 29 points with each point in the score corresponding to $3 \%$ of the left ventricular (LV) mass.

Table (1): Modified Selvester QRS scoring system ${ }^{(11)}$. 
- Echocardiography:

Resting transthoracic echocardiography was performed for all patients using the Vivid 9 system (GE Vingmed Ultrasound AS, Horten, Norway). Images were taken while the patient is supine or in left lateral position Three apical scans of the left ventricle in the three-chamber, four-chamber, and two-chamber views with ECG triggering according to the guidelines of the American Society of

\begin{tabular}{|c|c|c|c|c|c|}
\hline Lead & Duration (msec.) & Points & Amplitude Ratios & Points & $\begin{array}{l}\text { Max Leads } \\
\text { Points }\end{array}$ \\
\hline I & $\mathrm{Q} \geq 30$ & (1) & $\mathrm{R} / \mathrm{Q} \leq 1$ & $(1)$ & 2 \\
\hline II & $\begin{array}{l}\mathrm{Q} \geq 40 \\
\mathrm{Q} \geq 30\end{array}$ & $\begin{array}{l}(2) \\
(1)\end{array}$ & & & 2 \\
\hline AVL & $\mathrm{Q} \geq 30$ & (1) & $\mathrm{R} / \mathrm{Q} \leq 1$ & (1) & 2 \\
\hline AVF & $\begin{array}{l}Q \geq 50 \\
Q \geq 40 \\
Q \geq 30\end{array}$ & $\begin{array}{l}\mathbf{( 3 )} \\
(2) \\
(1)\end{array}$ & $\begin{array}{l}\mathrm{R} / \mathrm{Q} \leq 1 \\
\mathrm{R} / \mathrm{Q} \leq 2\end{array}$ & $\begin{array}{l}\text { (2) } \\
\text { (1) }\end{array}$ & 5 \\
\hline V1 & $\begin{array}{l}\text { Any } Q \\
Q \geq 50 \\
Q \geq 40\end{array}$ & $\begin{array}{l}\mathbf{( 1 )} \\
(2) \\
(1)\end{array}$ & $\mathrm{R} / \mathrm{S} \geq 1$ & (1) & 4 \\
\hline $\mathbf{V 2}$ & $\begin{array}{c}\text { Any } \mathrm{Q} \text { or } \mathrm{R} \leq 20 \\
\mathrm{R} \geq 60 \\
\mathrm{R} \geq 50\end{array}$ & $\begin{array}{l}\mathbf{( 1 )} \\
(\mathbf{2}) \\
(\mathbf{1}) \\
\end{array}$ & $\mathrm{R} / \mathrm{S} \geq 1.5$ & (1) & 4 \\
\hline $\mathbf{V 3}$ & Any $\mathrm{Q}$ or $\mathrm{R} \leq 30$ & (1) & & & 1 \\
\hline V4 & $\mathrm{Q} \geq 20$ & (1) & $\begin{array}{c}\mathrm{R} / \mathrm{Q} \text { or } \mathrm{R} / \mathrm{S} \leq 0.5 \\
\mathrm{R} / \mathrm{Q} \text { or } \mathrm{R} / \mathrm{S} \leq 1\end{array}$ & $\begin{array}{l}(2) \\
(1) \\
\end{array}$ & 3 \\
\hline V5 & $\mathrm{Q} \geq 30$ & (1) & $\begin{array}{l}\mathrm{R} / \mathrm{Q} \text { or } \mathrm{R} / \mathrm{S} \leq 1 \\
\mathrm{R} / \mathrm{Q} \text { or } \mathrm{R} / \mathrm{S} \leq 2\end{array}$ & $\begin{array}{l}(2) \\
(1)\end{array}$ & 3 \\
\hline V6 & $\mathrm{Q} \geq 30$ & (1) & $\begin{array}{l}\mathrm{R} / \mathrm{Q} \text { or } \mathrm{R} / \mathrm{S} \leq 1 \\
\mathrm{R} / \mathrm{Q} \text { or } \mathrm{R} / \mathrm{S} \leq 3\end{array}$ & $\begin{array}{l}(2) \\
(1)\end{array}$ & 3 \\
\hline
\end{tabular}

Echocardiography were performed ("i). Two examinations were done, the first is immediately after reperfusion and the second is 3 months later.

\section{The following measurements were taken:}

(A) Ejection fraction (EF): The LV volumes and ejection fraction (EF) were determined using the modified Simpson biplane technique from the apical 4- and 2-chamber views.

It is calculated also from the formula:

$\mathbf{E F}=[(\mathbf{E D V}-\mathbf{E S V}) / \mathbf{E D V}] \times \mathbf{1 0 0}$

Normally it is $50-70 \%{ }^{(1)}$.

(B) Strain echocardiography using the speckle tracking technique (STE):

STE is an echocardiographic, non-Doppler method that analyzes the longitudinal strain (LS) of LV segments by assessing the deformation of an object relative to its original length. STE is performed in typical apical views with frame rate of 60 to $90 \mathrm{frames} / \mathrm{sec}$, and strain will be automatically measured. W exclude patients whom more than four segments can't be analyzed due to poor image quality. The system generates curves of LS for each segment of the left ventricle, from which we estimate peak longitudinal strain (LS) during the cardiac cycle. Peak systolic strain was defined as the peak negative strain value during systole ${ }^{(1 ;)}$.

Global longitudinal strain (GLS) is calculated as the range of the values of different LV segments from the three apical views ${ }^{(8)}$. GLS measures less than $(-20 \%)$ is considered abnormal ${ }^{\left({ }^{9}\right)}$.

- Reperfusion of acute STEMI: 
Reperfusion of acute STEMI was done in all patients using thrombolytic therapy or primary PCI. Primary PCI was done using femoral or radial access. Imaging the non-infarct related artery (non-IRA) was done first. Then, IRA angiogram was done, thrombus aspiration and glycoprotein IIb-IIIa inhibitors infusion was done in high thrombus burden lesions. TIMI III flow, grade III myocardial blush and corrected TIMI frame count (CTFC) less than 27 were achieved in all patients.

\section{STATISTICAL ANALYSIS}

Data were then imported into Statistical Package for the Social Sciences (SPSS version 20.0) software for analysis. Quantitative data were expressed as means \pm SD and qualitative data were expressed as absolute frequencies (number) \& relative frequencies (percentage). Differences between means in two parametric groups were compared by Student's t test. Non-parametric data by Chi-square test. Bivariate correlation was used to study association between two continuous variables. Multivariate Logistic regression analysis was used to detect independent predictor of certain parameter. $\mathrm{P}$ value was set at $<0.05$ for significant results $\&<0.001$ for high significant results ${ }^{(15)}$.

\section{RESULTS}

In our study, we enrolled 400 patients with first time acute STEMI who were admitted to the coronary care unit (CCU) and cathlab. units of cardiology department at Zagazig University, Egypt and Kaohsiung Chang Gung Memorial Hospital, Taiwan during the period from November 2015 to November 2017.

Table (2): Demographic data and risk Factors in study groups

\begin{tabular}{|c|c|c|c|c|c|c|}
\hline Variab & & $\begin{array}{c}\text { Group I } \\
\text { (Thrombolysis) } \\
(\mathbf{N}=\mathbf{2 0 0})\end{array}$ & $\begin{array}{l}\text { Group II } \\
\text { (PPCI) } \\
(\mathbf{N}=200)\end{array}$ & $\begin{array}{c}\text { t-test } \\
\text { (t) }\end{array}$ & $\begin{array}{c}\text { Chi- } \\
\text { Square } \\
\text { test }\left(\chi^{2}\right)\end{array}$ & $P$ value \\
\hline $\begin{array}{c}\text { Age }(\text { yea } \\
\text { Mean } \pm\end{array}$ & & $57.1 \pm 11.6$ & $58.2 \pm 9.8$ & 0.6 & & $0.042(\mathrm{NS})$ \\
\hline Condor. & Male & $130(65 \%)$ & $120(60 \%)$ & & & ( 27 (NC) \\
\hline Genuer & Female & $70(35 \%)$ & $80(40 \%)$ & & 0.3 & $0.2 /$ (IV) \\
\hline$I^{\circ}$ & Yes & $124(62 \%)$ & $120(60 \%)$ & & 0 & $0=1$ (T) \\
\hline & No & $76(38 \%)$ & $80(40 \%)$ & & & \\
\hline Diabetes & Yes & $140(70 \%)$ & $134(67 \%)$ & & 0.2 & 020 \\
\hline Mellitus & No & $60(30 \%)$ & $66(33 \%)$ & & & $0.53(\mathrm{NSS})$ \\
\hline Smoking & Yes & $160(80 \%)$ & $154(77 \%)$ & & 0.1 & $038(\mathbf{N S})$ \\
\hline & No & $40(20 \%)$ & $46(23 \%)$ & & & 0.58 (NS) \\
\hline Drclinidemis & Yes & $123(61.5 \%)$ & $53(26.5 \%)$ & & 5.6 & $001 *(\mathbf{C})$ \\
\hline Dysinpiaema & No & $77(38.5 \%)$ & $147(73.5 \%)$ & & & $0.01 \%(3)$ \\
\hline
\end{tabular}


Table (3): Comparison of the percentage (\%) of ST resolution and QRS score reduction in the study groups

\begin{tabular}{|c|c|c|c|c|}
\hline Variable & $\begin{array}{c}\text { Group I } \\
(\text { Thrombolysis }) \\
(\mathrm{N}=200)\end{array}$ & $\begin{array}{c}\text { Group II } \\
(\mathrm{PPCI}) \\
(\mathrm{N}=200)\end{array}$ & $\begin{array}{c}\text { t-test } \\
(\mathrm{t})\end{array}$ & P value \\
\hline $\begin{array}{c}90 \text { min. ST resolution } \\
\text { Mean } \pm \text { SD }\end{array}$ & $\mathbf{0 . 7 0 \pm 0 . 1}$ & $\mathbf{0 . 8 5} \pm 0.2$ & 0.6 & $0.04 *(\mathbf{S})$ \\
\hline $\begin{array}{c}90 \text { min. QRS score } \\
\text { reduction } \\
\text { Mean } \pm \text { SD }\end{array}$ & $0.4 \pm 0.1$ & $0.6 \pm 0.2$ & 6.7 & $\mathbf{0 . 0 3 *}(\mathbf{S})$ \\
\hline
\end{tabular}

Table (4): shows the results of (Paired t-test) comparing the basal and follow-up echocardiographic parameters in each of the studied groups.

\begin{tabular}{|c|c|c|c|}
\hline Variable & $\begin{array}{c}\text { Group I } \\
\text { (Thrombolysis }) \\
(\mathbf{n = 2 0 0}) \\
\text { p-value }\end{array}$ & $\begin{array}{c}\text { Group II (PPCI) } \\
(\mathbf{n}=200) \\
\text { p-value }\end{array}$ & $\begin{array}{c}\text { t-test } \\
(\mathbf{t})\end{array}$ \\
\hline (Basal-3mo.) EF & $\mathbf{0 . 2 2}(\mathrm{NS})$ & $\mathbf{0 . 0 1} *(\mathrm{~S})$ & 3.3 \\
\hline (Basal-3mo.) GLS & $<0.001 * *(\mathrm{HS})$ & $<0.001 *($ HS $)$ & 0.4 \\
\hline
\end{tabular}

Table (5): Spearman Correlation between 3 months GLS value and different parameters in the study groups

\begin{tabular}{|c|c|c|}
\hline $\begin{array}{c}\text { Variable } \\
\text { Mean } \pm \text { SD }\end{array}$ & $\begin{array}{c}\text { Group I (Thrombolysis) } \\
\text { (N=200) }\end{array}$ & $\begin{array}{c}\text { Group II } \\
\text { (PPCI) } \\
(\mathbf{N}=\mathbf{2 0 0})\end{array}$ \\
\hline ST resolution & -0.6 & $<0.001 * *(\mathrm{HS})$ \\
\hline QRS score reduction & -0.4 & $<0.001 * *(\mathrm{HS})$ \\
\hline
\end{tabular}

Table (6): shows Receiving Operator Characteristic (ROC) analysis of the measured parameters showing, AUC, best cutoff, Sensitivity and specificity values (Diagnostic Accuracy) of the 90 minutes QRS score reduction for prediction of 3months GLS improvement.

\begin{tabular}{|c|c|c|c|c|}
\hline \multirow{2}{*}{ Area } & \multirow{2}{*}{ Asymptotic Sig. } & \multicolumn{2}{|c|}{ Asymptotic 95\% Confidence Interval } \\
\cline { 4 - 5 } & Std. Error & & Lower Bound & Upper Bound \\
\hline .599 & .055 & .098 & .491 & .707 \\
\hline
\end{tabular}




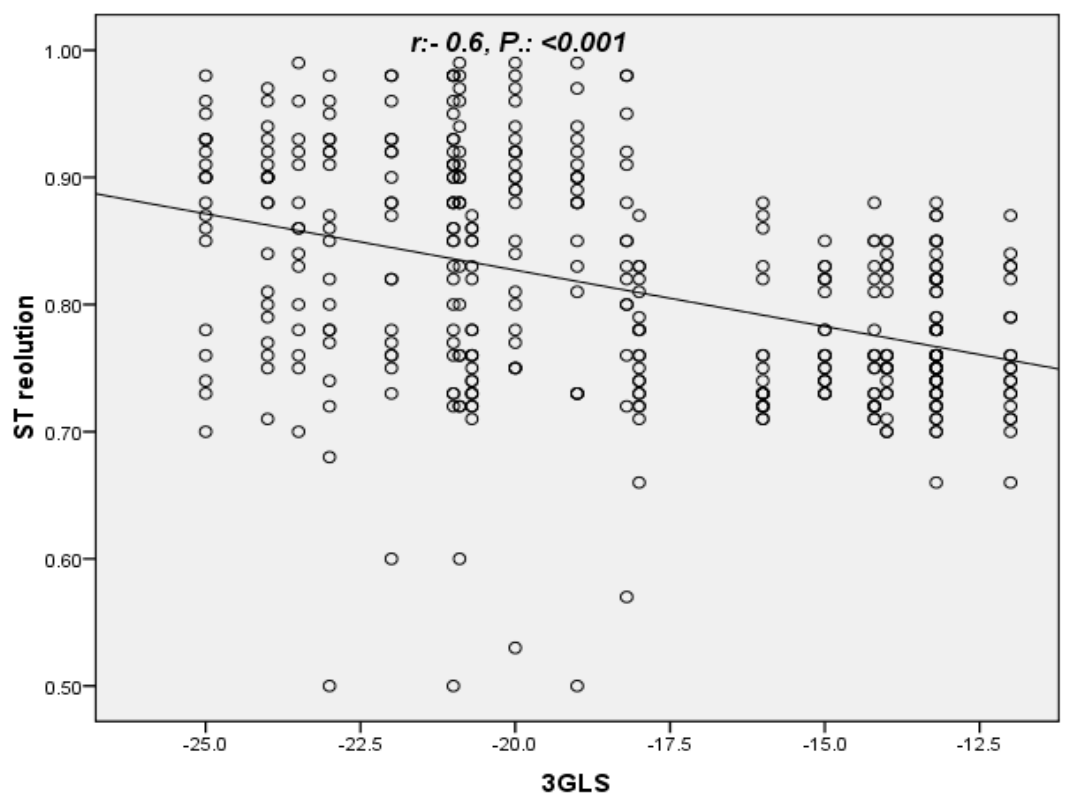

Figure (1): shows highly significant negative correlation between ST resolution and 3mo. GLS (r: -0.6$, P.: $<0.001 * *)$

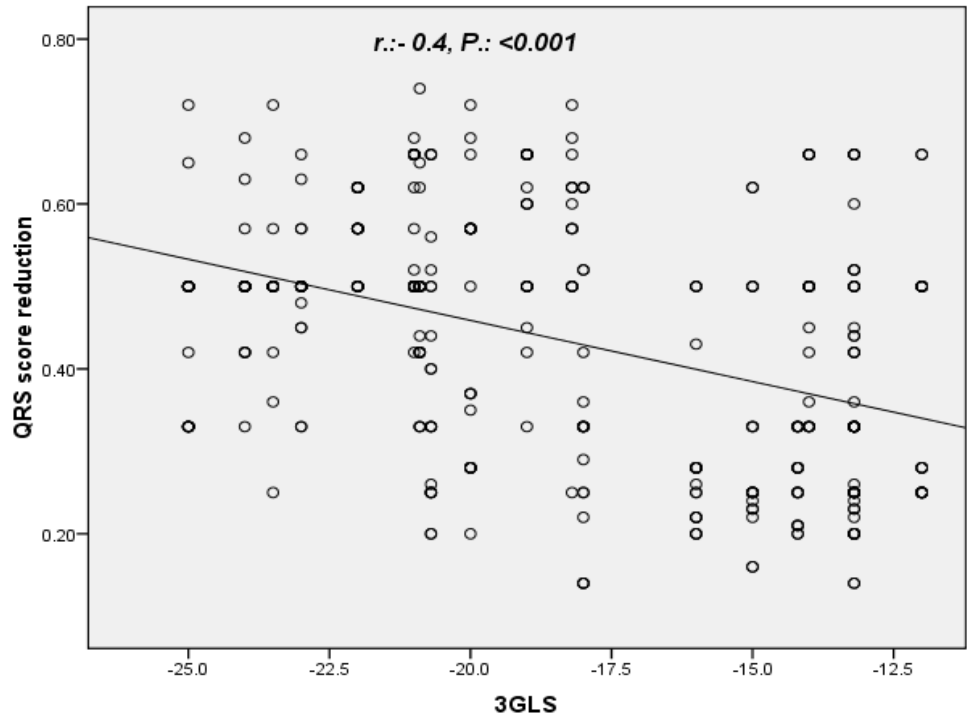

Figure (2): shows highly significant negative correlation between QRS score reduction and $3 \mathrm{mo.}$ GLS (r: -0.4, P.: $<0.001 * *)$ 


\section{ROC Curve}

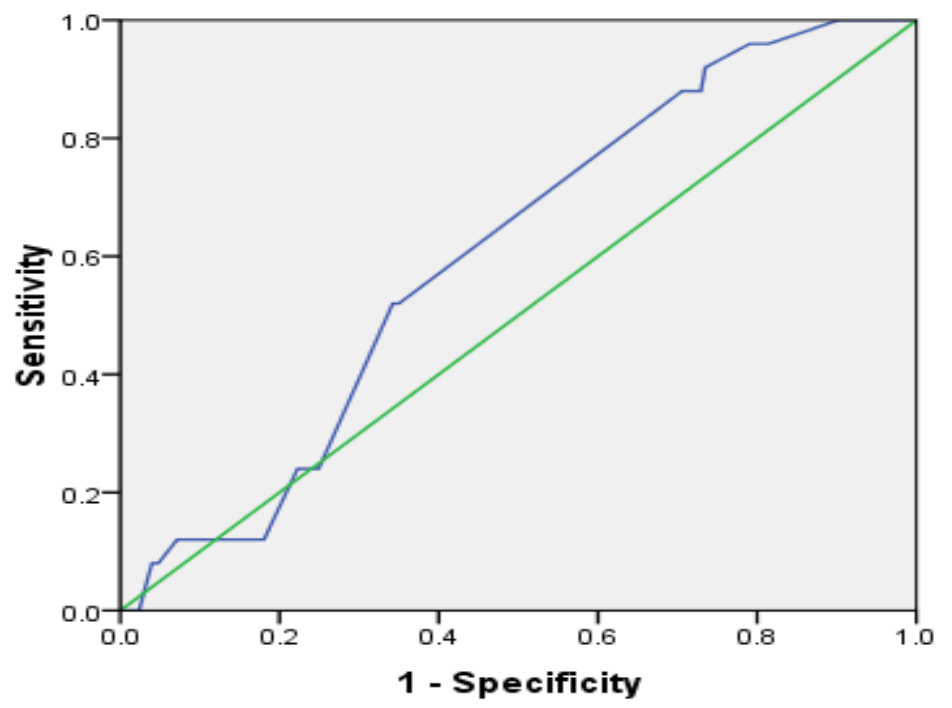

Diagonal segments are produced by ties.

Figure (3): shows Receiving Operator Characteristic (ROC) analysis of the measured parameters showing, AUC, best cutoff, Sensitivity and specificity values (Diagnostic Accuracy) of the 90 minutes QRS score reduction for prediction of 3months GLS improvement.

As regarding demographic data and risk Factors, there was non-significant difference between patients of both groups regarding age (P.: 0.42) and gender (P.: 0.27). Also, there was non-significant difference between both groups regarding the risk factors of coronary artery disease like hypertension (P.: 0.51), diabetes mellitus (P.: 0.33) and smoking (P.: 0.38). But there was significant statistical difference between both groups regarding dyslipidemia (P.: 0.01).

As regarding ECG data, 90 minutes ST resolution and QRS score reduction were significantly higher in PPCI group (P.: 0.04*, $0.03 *)$.

As regarding echocardiographic data, patients in group I had non-significant improvement of EF (P.: 0.22) during follow-up, but highly significant improvement of GLS (P.: $<0.001 * *) \quad$ compared to the basal echocardiographic study.

Patients in group II had significant improvement of EF (P.: 0.01*) during follow- up, and highly significant improvement of GLS (P.: <0.001**) compared to the basal echocardiographic study.

As regarding correlation with 3 months GLS value, there was highly significant negative correlation between $3 \mathrm{mo}$. GLS and ST resolution (Figure 1) and QRS score reduction (Figure 2) (P.: <0.001**).

ROC curve analysis shows that 90 minutes QRS score reduction has the best cut off value of $70 \%$ to predict 3months GLS improvement with $80 \%$ sensitivity and $79 \%$ specificity (Figure 3).

\section{DISCUSSION}

QRS score plays an important role for early risk stratification for STEMI (2). High QRS score is considered as an independent predictor of incomplete ST recovery and 30-day MACE in STEMI treated with primary PCI ${ }^{(\mathbf{1 6})}$.

Relying on GLS for estimation of infarct size after PCI of STEMI patients was more accurate than LVEF. As GLS is a cheap 
simple bedside test, it has a better economic value ${ }^{(17) .}$

Our study showed that there was nonsignificant difference between patients of both groups regarding age (P.: 0.42) and gender (P.: 0.27). Also, there was non-significant difference between both groups regarding the risk factors of coronary artery disease like hypertension (P.: 0.51), diabetes mellitus (P.: 0.33 ) and smoking (P.: 0.38), but significant regarding dyslipidemia (higher in thrombolysis group) (P.: 0.01).

Thus, our sample population is to an extent matched. we can notice that among our sample size, Taiwanese population had less incidence of dyslipidemia compared to Egyptian population. We attribute that to less caloric diet, more exercise program adoption and heathier lifestyle.

Our study showed that 90 minutes ST resolution was significantly higher in PPCI group (P.: 0.04*) and this is in agreement with Rahman et al., 2016 which reported that STsegment resolutions were significantly more in PPCI than thrombolysis at 90 minutes $(73.15 \pm 18.76 \text { vs } 60.06 \pm 23.33 \%, \mathrm{p}<0.015)^{(18)}$.

Our study showed that 90 minutes QRS score reduction was significantly higher in PPCI (P.: 0.03*).

Abdel-Salam et al., 2010 reported that the mean QRS score was significantly lower in the ST resolution group compared to the nonresolution group $(2.88+/-1.34$ vs $5.93+/-1.56$, respectively, $\mathrm{p}<0.001)^{(\mathbf{1 9})}$.

Our results showed that, there was nonsignificant difference between echocardiographic parameters of the studied groups during the acute STEMI (P.: 0.08 for basal EF and 0.2 for basal GLS, however all parameters in both groups denote impaired systolic and diastolic LV function during acute STEMI (Stunning).

$\mathrm{EF}$ is a non-reliable marker of systolic function in early stage after MI ${ }^{(20)}$ as stunning may overestimate the MI induced systolic dysfunction $^{(21)}$.

But the follow-up parameters showed more significant improvement of $\mathrm{LV}$ function in PPCI group (P.: 0.02* for 3mo. EF, $<0.001^{* *}$ for $3 \mathrm{mo}$. GLS). Similar results were reported by Ottervanger et al.,2001 ${ }^{(22)}$.

GLS as measured immediately after primary $\mathrm{PCI}$ is a reliable predictor of $\mathrm{LV}$ remodeling and long-term clinical outcomes represented by major adverse cardiac events (MACE) ${ }^{(23)}$.

Liszka et al., 2014 suggested that impaired LV deformation indices measured 3 days and 30 days after AMI may provide important predictive value in LV remodeling and patients' prognosis ${ }^{(24)}$.

Our results showed highly significant negative correlation between 3months GLS and (ST resolution and QRS score reduction) (P.: $\left.<0.001^{* *}\right)$.

The absence of ST-segment elevation resolution after PCI or fibrinolysis has been associated with poor prognosis, including larger infarct size and increased mortality ${ }^{(25)}$.

Also our results agree with Watanabe et al., 2015 who indicated that the QRS score derived from simple and widely available ECG may be a useful parameter for confirming the presence or absence of microvascular obstruction $^{(3)}$.

ROC curve analysis shows that 90 minutes QRS score reduction has the best cut off value of $70 \%$ to predict 3months GLS improvement with $80 \%$ sensitivity and $79 \%$ specificity (Figure 3 ).

It may be claimed that the primary endpoint is a subjective marker rather than a hard clinical endpoint. However, due to low event rate of MACE in the studied popuation, LV systolic function recovery represented by 3 months GLS improvement exemplifies a valid surrogate endpoint to detect the differences in outcomes of the treatment strategies adopted.

\section{CONCLUSIONS}

GLS measurement (compared to EF) early after STEMI is a reliable predictor for myocardial functional recovery assessed 3 months later, which surely would be expressed on the clinical outcomes. PPCI leads to better myocardial salvage compared with fibrinolysis. Modified Selvester QRS score reduction 90 
minutes after reperfusion is a cheap bedside ECG parameter added to ST resolution, can be considered as a reliable predictor of future myocardial salvage with its impact on longterm clinical outcome and modifying management strategies.

\section{Limitations}

Due to low event rate in selected lowintermediate risk STEMI patient, we couldn't rely on major adverse cardiac event (MACE) as a hard clinical endpoint to validate the QRS score for prediction of long-term outcomes.

\section{REFERENCES}

(1) Ferenc $M$ and Neumann F.J: Efficacy of primary PCI: the microvessel perspective, European Heart Journal Supplements, Volume 7, Issue suppl_I, 2005, Pages I4I9, https://doi.org/10.1093/eurheartj/sui061

(2) Hiroki Shiomi, Masami Kosuge, Takeshi Morimoto, Hiroki Watanabe, Tomohiko Taniguchi, Kenji Nakatsuma, et al, on behalf of the CREDO-Kyoto AMI Investigators. QRS Score at Presentation Electrocardiogram Is Correlated With Infarct Size and Mortality in STSegment Elevation Myocardial Infarction Patients Undergoing Primary Percutaneous Coronary Intervention. Circ J 2017; 81: 11291136 doi:10.1253/circj.CJ-16-1255.

(3) Watanabe N, Isobe $\mathrm{S}$, Okumura T, Mori H, Yamada T, Nishimura K, et al. Relationship between QRS score and microvascular obstruction after acute anterior myocardial infarction. J Cardiol. 2016 Apr;67(4):321-6. doi: 10.1016/j.jjcc.2015.05.016. Epub 2015 Jul 7.

(4) Nayel AE, Sabet S and Sammy A: Prediction of Myocardial Salvage by Modified Selvester QRS Score in Patients with ST-Segment Elevation Myocardial Infarction After Primary PCI. J Am Coll Cardiol Intv. 2014;7(2_S):S13S13.

(5) Sjøli B, Ørn S, Grenne B, Ihlen H, Edvardsen $\mathbf{T}$, Brunvand $\mathbf{H}$. Diagnostic capability and reproducibility of strain by Doppler and by speckle tracking in patients with acute myocardial infarction. JACC Cardiovasc Imaging 2009; 2:24-33.

(6) Cimino S, Canali E, Petronilli V, Cicogna F, De Luca L, Francone M, et al.: Global and regional longitudinal strain assessed by twodimensional speckle tracking echocardiography identifies early myocardial dysfunction and transmural extent of myocardial scar in patients with acute ST elevation myocardial infarction and relatively preserved LV function European Heart Journal - Cardiovascular Imaging 2013 ;14, 805-811.

(7) Vartdal T, Brunvand H, Pettersen E, Smith HJ, Lyseggen E, Helle-Valle T, et al.: Early prediction of infarct size by strain Doppler echocardiography after coronary reperfusion. J Am Coll Cardiol. 2007;49:1715-1721.

(8) Patrianakos AP, Zacharaki AA, Kalogerakis A, Solidakis G, Parthenakis FI, Vardas PE. Twodimensional global and segmental longitudinal strain: are the results from software in different high-end ultrasound systems comparable? Echo Res Pract. 2015 Mar 1; 2(1): 29-39. Published online 2015 Feb 25. doi: 10.1530/ERP-14-0070. PMCID: PMC4676462.

(9) Lang R.M, Badano L.P, Mor-Avi V, Afilalo J, Armstrong A, Ernande L, et al.: GUIDELINES AND STANDARDS. Recommendations for Cardiac Chamber Quantification by Echocardiography in Adults: An Update from the American Society of Echocardiography and the European Association of Cardiovascular Imaging. Journal of the American Society of Echocardiography January 2015.

(10) Park SM, Hong SJ and Kim YH: Predicting Myocardial Functional Recovery After Acute Myocardial Infarction: Relationship Between Myocardial Strain and Coronary Flow Reserve: Korean Circ J 2010;40:639-644.

(11) Nayel AE, Sabet S, Sammy A, et al.: Prediction of Myocardial Salvage by Modified Selvester QRS Score in Patients with ST-Segment Elevation Myocardial Infarction After Primary PCI. J Am Coll Cardiol Intv.2014;7(2_S):S13S13.

(12) Hanekom L, Cand J, Jeffries L, Case C, Mundy J, Hawley C, et al.: Incremental value of strain rate analysis as an adjunct to wallmotion scoring for assessment of myocardial viability by dobutamine echocardiography: a follow-up study after revascularization. Circulation 2005; 112: 3892-3900.

(13) Albin G, Rohko and Rademark E: Comparison of echocardiographic quantification of left ventricular ejection fraction to radio nucleotide angiography in patients with regional wall motion abnormalities. Am.J.Cardiol 1990; 65:103.

(14) Sjoli B, Grenne B and Smiseth OA: The advantage of global strain compared to left ventricular ejection fraction to predict outcome after acute myocardial infarction. Echocardiography 2011; 28:556-563.

(15) Dean JA and Coulabier D.: A word processing database and statistic program for 
epidemiology on microcomputer CDC 2000, Atlanta, Gorgia, USA.

(16) Huseyin Uyarel, Nese Cam, Ertan Okmen, Hulya KasVkcVoglu, Zeynep Tartan, Ozgur Akgul, et al. Level of Selvester QRS score is predictive of ST-segment resolution and 30-day outcomes in patients with acute myocardial infarction undergoing primary coronary intervention. Am Heart J 2006;151:1239.e121239.e7.

(17) Amira M.Ismail, Wael Samy, Randa Aly, Suzy Fawzy, Khaled Hussein. Longitudinal strain in patients with STEMI using speckle tracking echocardiography. Correlation with peak infarction mass and ejection fraction. https://doi.org/10.1016/j.ejccm.2015.10.002.

(18) Hasanur Rahman, Syeda Fahmida Afrin, Aminul Islam, Saqif Shahriar, Abu Zahid and Mohammad Badiuzzaman. Comparison of STsegment resolution influencing in hospital outcome after primary percutaneous coronary intervention and fibrinolysis (with streptokinase) in patients with acute ST-segment elevation myocardial infarction. Bangladesh Journal of Medical Science. 2016; Vol 15, No 2.

(19) Abdel-Salam Z, Wafa S, Kamel S, Nammas W. The modified Selvester QRS score: can we predict successful ST segment resolution in patients with myocardial infarction receiving fibrinolytic therapy? Cardiol J. 2010;17(4):36773.

(20) Mele D. Left ventricular ejection fraction: Pathophysiological aspects and intrinsic limitations. G Ital Cardiol (Rome) 2012;13:793808. [PubMed]
(21) Munk K, Andersen NH, Nielsen SS, Bibby BM, Bøtker HE, Nielsen TT, et al. Global longitudinal strain by speckle tracking for infarct size estimation. Eur

Echocardiogr. 2011;12:156-65. [PubMed]

(22) Ottervanger JP1, van 't Hof AW, Reiffers S, Hoorntje JC, Suryapranata H, de Boer MJ, et al. Long-term recovery of left ventricular function after primary angioplasty for acute myocardial infarction. Eur Heart J. 2001 May;22(9):785-90.

(23) Lacalzada, Juan \& de la Rosa, Alejandro \& Manuela Izquierdo, María \& José Jiménez, Juan \& Luis Iribarren, José \& GarcíaGonzález, Martín \& Marí, Belén \& Amelia Duque, María \& Barragán, Antonio \& Hernández, Celestino \& Carrillo-Pérez, María \& Cerdeña, Ignacio. Left ventricular global longitudinal systolic strain predicts adverse remodeling and subsequent cardiac events in patients with acute myocardial infarction treated with primary percutaneous coronary intervention. The international journal of cardiovascular imaging 2015. 31.10.1007/s 10554-015-0593-2.

(24) Liszka J, Haberka M, Tabor Z, Finik M, Gąsior Z: Two-dimensional speckle-tracking echocardiography assessment of left ventricular remodeling in patients after myocardial infarction and primary reperfusion. Arch Med Sci 2014; 10, 6: 1091-1100. DOI: 10.5114/aoms.2014.47821.

(25) de Lemos JA and Braunwald E: ST segment resolution as a tool for assessing the efficacy of reperfusion therapy. J Am Coll Cardiol 2001; 38: 1283-1294. 